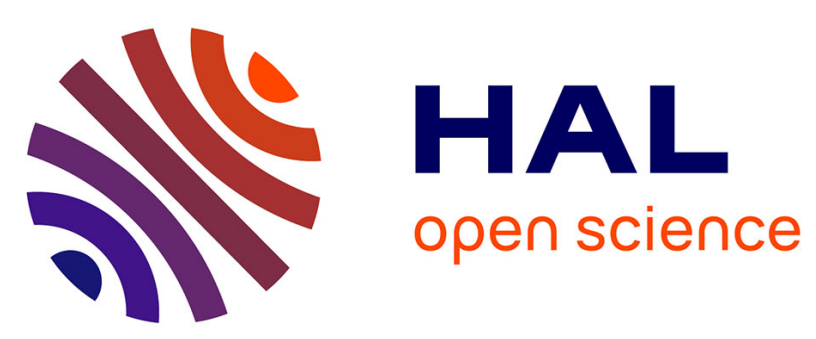

\title{
Experimental investigation of the strain-rate effects on the failure of composite materials with off-axis tensile tests on unidirectional plies
}

Thomas Fourest, Julien Berthe

\section{- To cite this version:}

Thomas Fourest, Julien Berthe. Experimental investigation of the strain-rate effects on the failure of composite materials with off-axis tensile tests on unidirectional plies. Strain, 2021, 57 (4), pp.e12385. $10.1111 /$ str.12385 . hal-03283851

\section{HAL Id: hal-03283851 \\ https://hal.science/hal-03283851}

Submitted on 12 Jul 2021

HAL is a multi-disciplinary open access archive for the deposit and dissemination of scientific research documents, whether they are published or not. The documents may come from teaching and research institutions in France or abroad, or from public or private research centers.
L'archive ouverte pluridisciplinaire HAL, est destinée au dépôt et à la diffusion de documents scientifiques de niveau recherche, publiés ou non, émanant des établissements d'enseignement et de recherche français ou étrangers, des laboratoires publics ou privés. 
DOI: $\mathrm{xxx} / \mathrm{xxxx}$

\title{
ARTICLE TYPE
}

\section{Experimental investigation of the strain-rate effects on the failure of composite materials with off-axis tensile tests on UD-plies}

\author{
Thomas Fourest* | Julien Berthe
}

${ }^{1}$ DMAS, ONERA, F-59014 Lille - France

Correspondence

*Thomas Fourest, ONERA, 5, rue des Fortifications, CS 9001359045 Lille Cedex

Email: thomas.fourest@onera.fr

\begin{abstract}
Summary
The present study experimentally investigates the mechanical response of T700/M21 Carbon Fibre Reinforced Polymers subjected to coupled shear and transverse tension at intermediate strain-rates ranging from $10^{-3} \mathrm{~s}^{-1}$ to $15 \mathrm{~s}^{-1}$. Off-axis tension specimens with transverse and oblique tabs are used for the various tests. Moreover, the specimen aspect ratio is quite low, since dynamic tests are performed in this study. The axial stress-strain curves are successfully simulated using Finite Element simulations with a visco-elastic model. Based on these numerical simulations, specific stress correction factors are computed to take the effect of end-constraints into account for such low aspect ratio specimens. Finally, an increase in the material strength with the strain-rate is observed.
\end{abstract}

\section{KEYWORDS:}

Failure criteria, off-axis tensile test, unidirectional composite, visco-elasticity

\section{1 | INTRODUCTION}

The experimental characterization and the modelling of the behavior of laminated composites under quasi-static loading conditions have been intensely studied, in particular thanks to the various World Wide Failure Exercises [23, 7, 9]. Following these exercises, an increase of interest in the rate-dependent behavior law has been observed [5, 22, 27].

The physical justification of the various rate effects introduced in these models is classically based on compressive high strain rate tests on off-axis specimens [28, 29, 19, 12]. The use of off-axis specimens allows a coupling to be induced between tension (or compression) and shear in the specimen, using a single actuator and simple specimens, which explains the interest of the various authors in these tests, particularly when dealing with the dynamic testing. Some authors [21, 14, 30] have used off-axis specimens under tension to study the failure of Carbon Fiber Reinforced Polymer (CRFP) materials. Less studies have investigated the dependency on the strain-rate. An example is the work of Tanigushi et al. [26], which used oblique tab off-axis specimens and Split Hopkinson Tension Bars leading to strain-rates above the range of interest of this study. The use of oblique tabs permits the unwanted transverse load to be limited in tensile off-axis tests. For compressive testing, the transverse load is classically neglected by reducing the friction between the specimen and the testing machine. For the tensile test, the specimen has to be held with a gripping system. Consequently, the unwanted transverse load leads to a more complicated analysis, even more for dynamic tests which can explain that compressive tests have been preferred in the literature.

The aim of this work is to develop a methodology to characterize the rate dependency of the failure of a CRFP ply subjected to coupled tension and shear loadings. The range of strain-rates targeted is between $10^{-3} \mathrm{~s}^{-1}$ and $100 \mathrm{~s}^{-1}$. The preferred testing devices for these strain-rates are servo-hydraulic jacks. In this study, the use of oblique tabs is proposed, in order to reduce the unwanted transverse load. We focus specifically on the influence of the specimen aspect ratio which modify the length that can 
freely deform in order to be able to reduce it for the dynamic testing investigation. Finally, the test results are presented and analyzed for three different loading rates on a servo-hydraulic jack.

\section{I SPECIMEN GEOMETRY FOR DYNAMIC TESTING}

The advantage of off-axis specimens is the apparent simplicity of the test, however their drawback is that they induce an unwanted transverse load to the testing device. In addition to increasing the complexity of the analysis, this could prevent the use of such specimens on servo-hydraulic jacks, since they are usually not build to withstand high transverse loads. One way of dealing with this drawback is the use of long specimens (for instance an aspect ratio of 12.5 in [30]) and corrective factors [18]. However, such long specimens are not suitable for high strain-rate tests, since it would lead to smaller strain-rates for the same actuator speed and it would amplify resonance of the load chain and pollute the load signal recording. It would also lead to longer times to reach mechanical equilibrium. The investigated solution in this study is the use of oblique tabs on such specimens (Figure 1). Oblique tabs are designed to diminish the transverse load and homogenize the stress fields. Indeed, Sun and Chung [25] showed that the stress distribution is more homogeneous in the specimen using these tabs and that it results in a better shear modulus measurement without the use of correction factors. Pierron and Vautrin [21] extended the analysis of the effect of such procedure to the characterization of the strength of unidirectional composites. They observed that, unlike for straight tab specimens, the failure occurred in the gauge section using oblique tabs for an aspect ratio of $9(L / w$ in Figure 1). However, they concluded that the presence of transverse stresses in the specimen prevents the determination of the in-plane shear strength. Although it appears as a limitation in their study, the investigation of the effect of the strain-rate on the failure of unidirectional specimens subjected to coupled shear and transverse stresses is of interest, so these specimens seem quite appropriate.

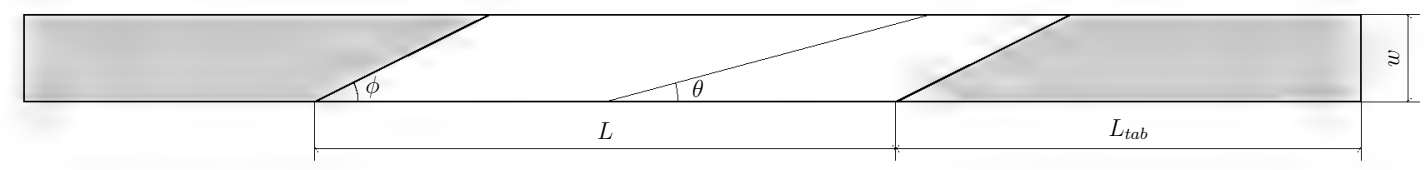

FIGURE 1 Schematics of oblique tabs off-axis specimens.

\section{1 | Material}

The material used in this study is the Hexply M21/35\%/268/T700GC (Hexcel France) made of T700 carbon fibers and M21 epoxy resin. The unidirectional plates have been manufactured with a typical cure cycle in an autoclave after a hand lay-up procedure. The various specimens have been cut out of the plates with a diamond saw. The quasi-static and dynamic elastic properties have been characterized by various authors. The values used in this study to compute oblique tabs have been taken from the $\mathrm{PhD}$ thesis of J. Berthe [1]. Table 3 summarizes these numerical values.

\section{2 | Computation of oblique tab angles}

The theory used to define the angle of oblique tabs is the linear elastic theory. To compute the angle of oblique tabs, Sun and Chung [25] considered that the off-axis specimen is subjected to a uniaxial stress $\sigma_{x x}$. Under this assumption, the state of strain is given as :

$$
\begin{aligned}
\varepsilon_{x x} & =\bar{S}_{11} \cdot \sigma_{x x} \\
\varepsilon_{y y} & =\bar{S}_{12} \cdot \sigma_{x x} \\
\tau_{x y} & =\bar{S}_{16} \cdot \sigma_{x x}
\end{aligned}
$$

where $\bar{S}_{i j}$ are the compliance coefficient in the global coordinate system. Consequently, a shear deformation occurs when subjected to a normal load, except when the global coordinate system coincides with that of the material. Then, assuming elastic deformation of the specimen, the angle between the isodisplacement lines and the longitudinal axis can be computed. The 
TABLE 1 Correspondence between the off-axis angle $\theta$ and the oblique tab angle $\phi$ for T700/M21.

\begin{tabular}{cccccc}
\hline$\theta$ & $15^{\circ}$ & $30^{\circ}$ & $45^{\circ}$ & $60^{\circ}$ & $75^{\circ}$ \\
$\phi$ & $23.5^{\circ}$ & $37^{\circ}$ & $56^{\circ}$ & $74^{\circ}$ & $85^{\circ}$ \\
\hline
\end{tabular}

oblique tab angle is based on this angle $\phi$, given by Equation (2). Table 1 summarizes the correspondence between the off-axis angle of the specimen and the oblique angle of the tab.

$$
\operatorname{cotan}(\phi)=-\frac{\bar{S}_{16}}{\bar{S}_{11}}
$$

\section{3 | Effect of the specimen length/width aspect ratio on the transverse load}

Oblique tabs have been mainly used for quasi-static tests with high aspect ratio. However, for high strain-rate tests, the specimen length should be reduced in order to reach higher strain-rates for the same actuator speed. Additionally shorter specimens will reduce the time required to reach dynamic equilibrium for the high strain-rate tests. For instance, Taniguchi et al. [26] used specimens with a length of $25 \mathrm{~mm}$ and a width of $5 \mathrm{~mm}$ (aspect ratio of 5) to perform high strain-rate tension tests with Split Hopkinson Pressure bars. However, in an attempt to limit free edge effects, a width of $15 \mathrm{~mm}$ will be considered in the present study. Consequently, lower aspect ratios have to be studied. The investigation of this effect numerically using Finite Element (FE) simulations is proposed. It would also help to understand the magnitude of the transverse load.

To perform this investigation the Z-set software has been used [17]. It is a FE software co-developed by École des Mines ParisTech and Onera. 3D computations are performed using prismatic 15 node quadratic elements. There are 4 elements in the specimen thickness. Triangular prismatic elements are selected, since the discretization of the tab angle tip would lead to highly distorted elements if more common hexahedral elements were used. The mean element size is about $1 \mathrm{~mm}$. An implicit solver is used in all of the present work. As in [21, 25], the tabs are not modelled, so only the angle between the boundary condition and the axis of the specimen changes. In practice, a specimen width $w=15 \mathrm{~mm}$ is used, the specimen length has been adapted to each case. The aspect ratio of 2.66 is the smallest that can be investigated. Indeed, to ensure that the fibres never bridge between the two end-tabs for all configurations, the aspect ratio of 2.66 is the smallest one that leaves an area that is free to deform in shear for a $15^{\circ}$ off-axis specimen which is the critical configuration. In all cases, a displacement leading to $1 \%$ of longitudinal strain is applied at one end of the specimen, while the other remains clamped, as shown in Figure 2 The external loads are then recovered and used to compute the transverse-over-longitudinal load ratio. Table 2 summarizes the ratio between the transverse force $F_{T}$ and the longitudinal force $F_{L}$ for all the tested cases. It can be seen that the $F_{T} / F_{L}$ levels obtained numerically for the 2.66 aspect ratio with straight tabs are quite important. However, with the oblique tabs, the $F_{T} / F_{L}$ levels are of the same order of magnitude as that of a straight tabbed specimen with an aspect ratio of 10, which are more reasonable. From these results, it can be concluded that the use of oblique tabs is even more important for short specimens because they tend to induce higher transverse load levels. From this analysis, these levels are considered low enough to proceed with the experiments.

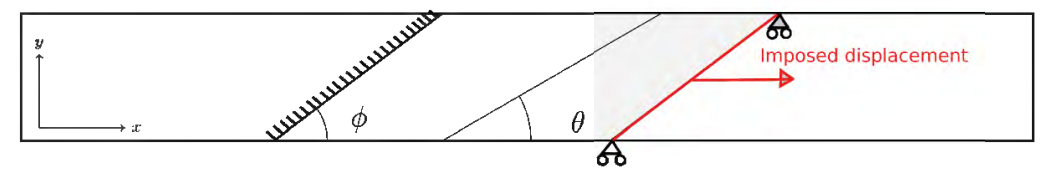

FIGURE 2 Boundary conditions of the FE simulations. Only the grey area is meshed. The nodes on the left end of the specimen free length have all degrees of freedom blocked. On the right end, the $y$ and $\mathrm{z}$ degrees of freedom are blocked and displacement along the $\mathrm{x}$ degree is imposed. 
TABLE 2 Longitudinal and transverse loads for $1 \%$ of longitudinal strain computed using the Z-Set software for straight and oblique tab specimens.

\begin{tabular}{cccccccc}
\hline & $L / w$ & & $15^{\circ}$ & $30^{\circ}$ & $45^{\circ}$ & $60^{\circ}$ & $75^{\circ}$ \\
\hline \multirow{4}{*}{ Straight tabs } & 10 & $F_{T} / F_{L}$ & $2.56 \%$ & $6.33 \%$ & $3.25 \%$ & $1.35 \%$ & $0.38 \%$ \\
\hline \multirow{2}{*}{ Oblique tabs } & 10 & $F_{T} / F_{L}$ & $16.46 \%$ & $19.08 \%$ & $11.01 \%$ & $4.46 \%$ & $1.19 \%$ \\
& 2.66 & $F_{T} / F_{L}$ & $-0.07 \%$ & $-0.62 \%$ & $-0.83 \%$ & $-1.04 \%$ & $-0.07 \%$ \\
& $F_{T} / F_{L}$ & $-2.23 \%$ & $-1.89 \%$ & $-0.61 \%$ & $0.18 \%$ & $0.09 \%$ \\
\hline
\end{tabular}

\section{I EXPERIMENTAL PROCEDURE}

\subsection{Synthesis: final specimen geometry for dynamic tests}

Figure 3 summarizes the dimensions of the off-axis tension specimens used for high strain rate tests. $[0]_{4}$ T700/M21 unidirectional lay-ups have been used to manufacture the specimens. Glass fiber tabs with a thickness of $1 \mathrm{~mm}$ have been used, as recommended by Pierron and Vautrin [21] for off-axis specimens. They are bonded to the specimen using Araldite 2014-1 adhesive. The length of the tabs was limited to $50 \mathrm{~mm}$ by the gripping device used, so that the complete length of the tabs was gripped by the device.

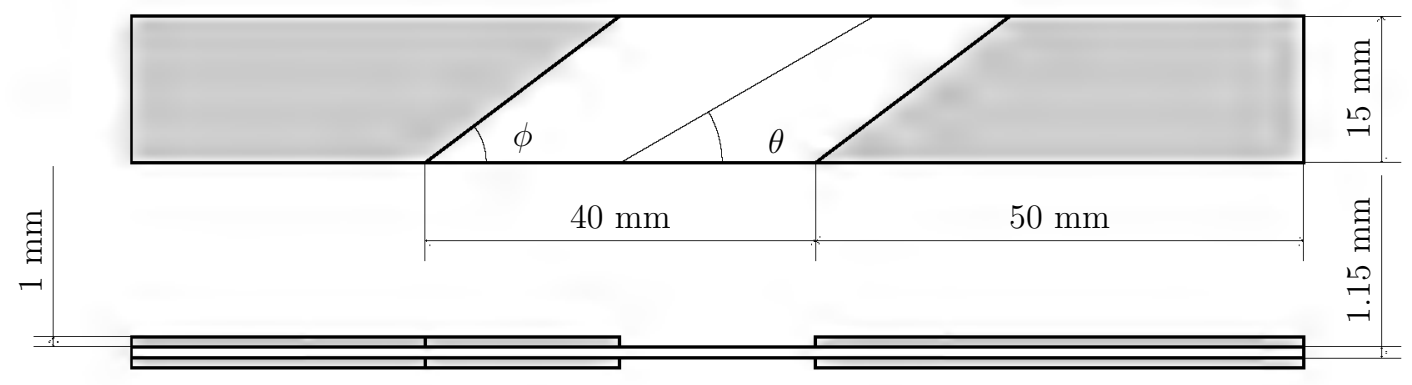

FIGURE 3 Oblique tab off-axis tension specimen geometry for high strain rate tests.

\section{2 | Test set-up}

The experimental set-up is described in Figure 4. The experimental investigation is performed using a SCHENCK servohydraulic jack. In this study, three different upper holder speeds will be studied: $5 \mathrm{~mm} / \mathrm{min}, 500 \mathrm{~mm} / \mathrm{min}$ and $1 \mathrm{~m} / \mathrm{s}$. For each speed, at least three specimens are tested in order to check discrepancies. The applied load is measured with a Kistler 9071 A piezo-electric load cell. A pre-stress load is applied on the load cell in order to be able to measure the load applied to the specimen between -200 and $+200 \mathrm{kN}$. To accurately evaluate the speed of the test, the upper holder displacement is measured with a KEYENCE LK-H052 laser transducer.

The specimen axial strain is measured with a 2-mm grid (TML YFLA-2) strain gauge, which is glued on the specimen surface. In addition to this measure, Digital Image Correlation (DIC) will be used to assess the homogeneity of the strain field prior to the failure. The images are recorded using an high speed Photron SA-X camera with a Micro NIKKOR $105 \mathrm{~mm}$ f/2.8 lens with two extension tubes of $12 \mathrm{~mm}$. The camera has a resolution of 1024x1024 pixels. For all DIC maps presented in this work, the full resolution of the camera is used and the camera frame rate is $50 \mathrm{fps}$. The field of view has been adapted dependending on the specimen off-axis angle. It is between $30 \mathrm{~mm}$ for $15^{\circ}$ off-axis specimens and $55 \mathrm{~mm}$ for $90^{\circ}$ specimens. It results in pixels size between $0.029 \mathrm{~mm}$ and $0.053 \mathrm{~mm}$. Finally, to synchronize all measurement systems and record data, a 1-MHz DEWETRON DEWE-2600 data acquisition system is used. 


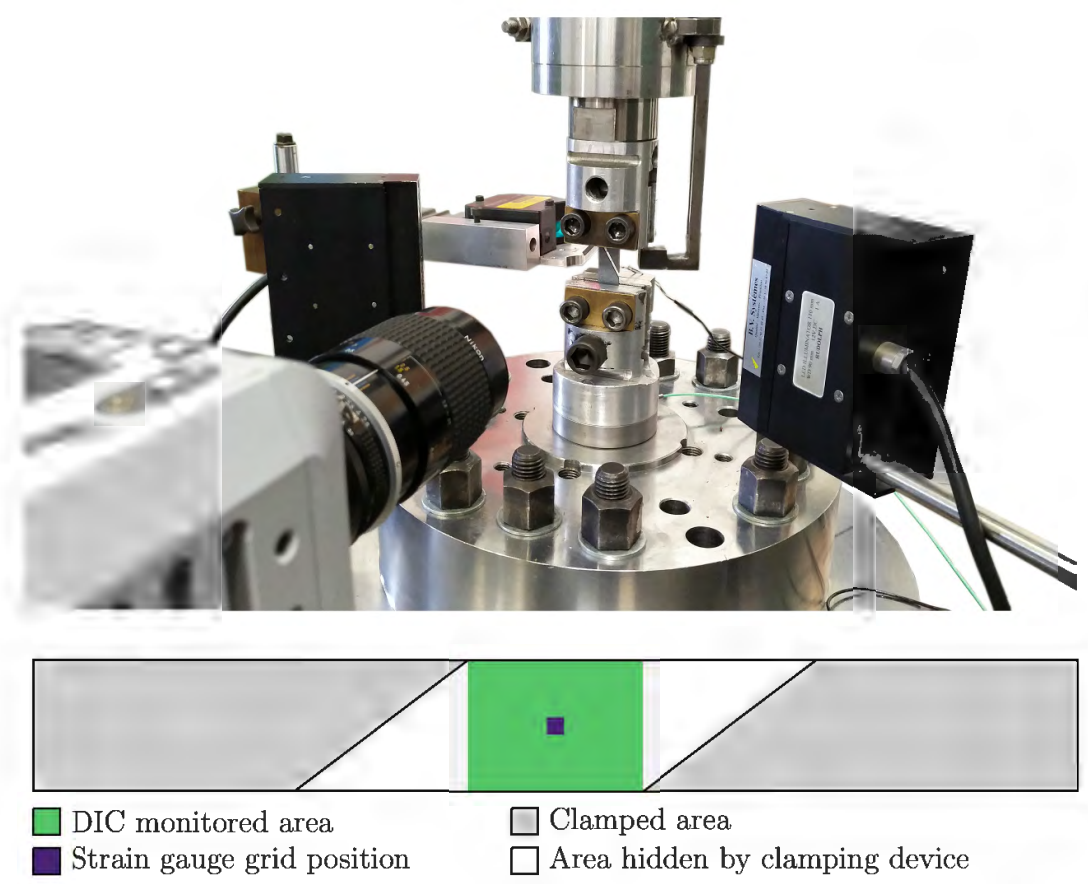

FIGURE 4 Experimental setup used to perform the high loading rate tests and schematics of the gauge and DIC measurement areas.

\section{4 | QUASI-STATIC EXPERIMENTAL VALIDATION}

Firstly, tests have been performed at a loading rate of $5 \mathrm{~mm} / \mathrm{min}$ which is the minimum of this actuator. A minimum of three specimens have been tested for all off-axis angles to assess repeatability. To ensure the absence of bending in the tests, a comparison between DIC and the strain gauge was performed in the gauge area. The mean axial strain computed by DIC is consistent with the one recorded by the strain gauge on the opposite side of the specimen, so the specimen is only subjected to in-plane loading. Figure 5 summarizes the axial stress-strain curves for all tested angles. The last points of the curves correspond to the failure of the specimen, from which the strength is determined. In the present work all stress-strain curves presented are typical results; it is presented in this way since the experimental discrepancy is low for the material behavior. The discrepancy in terms of failure is discussed later in the paper. It must be noted that for the $15^{\circ}, 30^{\circ}, 45^{\circ}$ and $60^{\circ}$ off-axis specimens the axial stress-strain response exhibits a non-linearity. Obviously, this non-linearity is not in agreement with the linear elastic behavior assumed to design the oblique tabs. This non-linearity in the axial stress-strain can also be observed in numerous studies, such as [10, 26, 11] for both rectangular and oblique tabs.

Uniaxial $5 \mathrm{~mm} / \mathrm{min}$ tests have also been performed on $0^{\circ}$ specimens to determine the longitudinal modulus. A value of 124.8 GPa has been measured using the ISO 257-5:1997[8] standard. From the $45^{\circ}$ off-axis tests the shear modulus has been determined and from the $90^{\circ}$ off-axis tests the transverse modulus has been determined. Table 3 summarizes these properties. The properties found in this study are lower than those determined in [1] that have been used for the tab angle computation. Fortunately, this variation observed between the measured values and the one used to compute tabs angles induces only very slight changes in the tab angle, with a maximum variation obtained for the $60^{\circ}$ configuration leading to a modification of the tab angle lower than $1.5^{\circ}$. Consequently, these variations are neglected in the sequel.

Based on these mechanical properties, the theoretical off-axis rigidities can be computed according to Equation (3) below:

$$
\begin{gathered}
Q_{11}^{\prime}(\theta)=\cos ^{4} \theta Q_{11}+\sin ^{4} \theta Q_{22}+2 \cos ^{2} \theta \sin ^{2} \theta Q_{12}+4 \cos ^{2} \theta \sin ^{2} \theta Q_{66} \\
\text { with }: Q_{11}=\frac{E_{L}}{1-v_{L T} \nu_{T L}} ; Q_{22}=\frac{E_{T}}{1-v_{L T} v_{T L}} ; Q_{12}=\frac{v_{T L} E_{L}}{1-v_{L T} v_{T L}} ; Q_{66}=G_{L T} \text { and } v_{T L}=v_{L T} \frac{E_{T}}{E_{L}}
\end{gathered}
$$

where $Q_{11}^{\prime}(\theta)$ is the rigidity of a $\theta$ angle off-axis specimen, and $Q_{11}, Q_{22}, Q_{12}$ and $Q_{44}$ are rigidities along the orthotropy axes.

Table 4 compares the various off-axis rigidities computed using this transformation law with those found experimentally. 


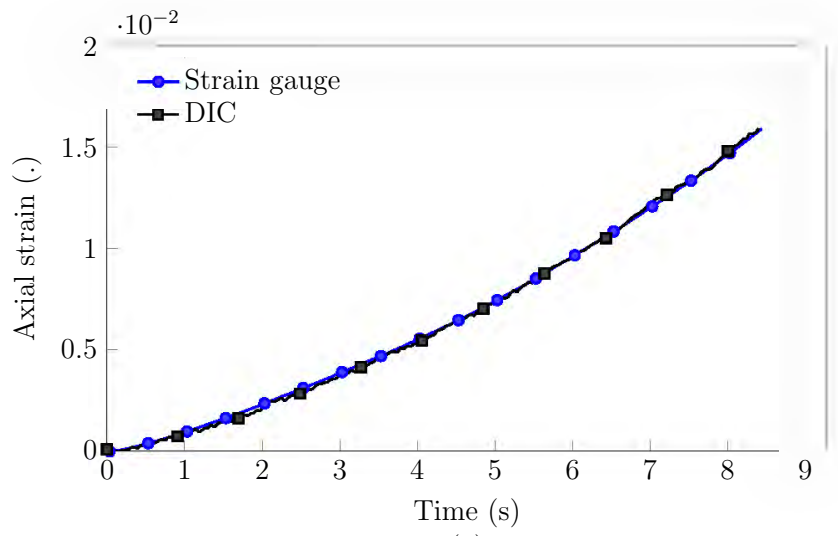

(a)

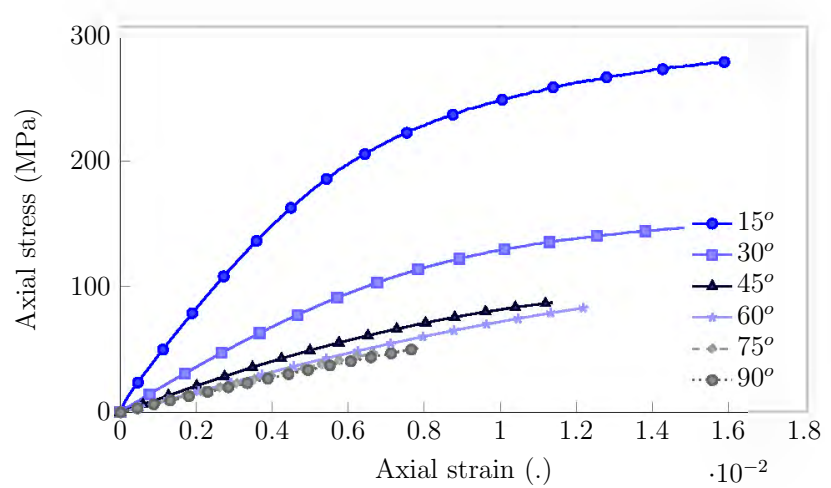

(b)

FIGURE 5 (a) Comparison of the strain measurement performed with the strain gauge on one side and using DIC on the opposite side of a $15^{\circ}$ off-axis specimen - (b) Axial stress-strain curves for a typical specimen for all tested off-axis angles at a $5 \mathrm{~mm} / \mathrm{min}$ loading rate.

TABLE 3 Main mechanical properties of the unidirectional composite.

\begin{tabular}{lcccc}
\hline & $\begin{array}{c}E_{L} \\
(\mathrm{GPa})\end{array}$ & $\begin{array}{c}E_{T} \\
(\mathrm{GPa})\end{array}$ & $v_{L T}$ & $\begin{array}{c}G_{L T} \\
(\mathrm{GPa})\end{array}$ \\
\hline from [1] & 136 & 8.08 & 0.31 & 4.5 \\
This study & 124.8 & 7.21 & - & 4.22 \\
\hline
\end{tabular}

A significant difference between the apparent rigidity predicted by the transformation law and that obtained experimentally can be observed for the $15^{\circ}$ off-axis specimens. This difference had already been noticed by Cai et al. [3] on glass/epoxy laminates for $15^{\circ}$ and $30^{\circ}$ off-axis specimens under tension. However they did not explain it.

TABLE 4 Comparison between off-axis apparent rigidities computed from the transformation law and those obtained experimentally.

\begin{tabular}{cccccc}
\hline Off-axis angle & $\begin{array}{c}15^{\circ} \\
(\mathrm{GPa})\end{array}$ & $\begin{array}{c}30^{\circ} \\
(\mathrm{GPa})\end{array}$ & $\begin{array}{c}45^{\circ} \\
(\mathrm{GPa})\end{array}$ & $\begin{array}{c}60^{\circ} \\
(\mathrm{GPa})\end{array}$ & $\begin{array}{c}75^{\circ} \\
(\mathrm{GPa})\end{array}$ \\
\hline Transformation law & 45.31 & 17.67 & 10.57 & 8.20 & 7.39 \\
Experimental & 37.94 & 17.48 & 10.26 & 8.46 & 7.04 \\
Difference & $16 \%$ & $1 \%$ & $3 \%$ & $3 \%$ & $4.5 \%$ \\
\hline
\end{tabular}

\section{1 | Finite Element simulations taking into account visco-elasticity}

To investigate the possible causes of the difference between the axial rigidity computed from the transformation law that obtained experimentally at $15^{\circ}$ and $30^{\circ}$, FE simulations have been performed. Linear elastic FE simulations, such as those performed in Section 2.3 do not reproduce this observation. Thus, the introduction of the end-constraint appears to be insufficient to explain this phenomenon. Since it is known that CFRP are time-dependent material and that there is no clear damage mechanism to consider for these loading cases, a visco-elastic model is considered. 


\subsection{1 | Spectral viscoelastic model}

The purpose of this study is to model the mechanical response of organic matrix composite materials under loadings of various strain rates. We focus on the variation of the tangent shear modulus $G_{12}$, which is known to be rate-dependent. One way of taking this phenomenon into account is to introduce a function $f$ to describe the evolution of the modulus, $G_{12}=f(\dot{\varepsilon})$, as, for example, in Song et al. [24]. The choice of $f$ is not simple and generally not physically based. Another way, considered in the present paper, is to use a visco-elastic behavior for the unidirectional ply. In the following work, a visco-elastic spectral model taken from Maire [16] is used. The visco-elastic behavior of the ply, in the local basis, can be written as:

$$
\sigma=C^{0}:\left(\varepsilon-\varepsilon^{v e}\right)
$$

where $\sigma$ is the Cauchy stress, $C^{0}$ is the elastic tensor, $\varepsilon$ is the total strain and $\varepsilon^{v e}$ is the viscous strain. In such an approach, the viscous strain is taken as the sum of elementary viscous mechanisms $\xi_{i}$, associated with a relaxation time $\tau_{i}$ and a weight $\mu_{i}$ :

$$
\dot{\varepsilon}^{v e}=g(\sigma) \sum_{i} \dot{\xi}_{i} \quad \text { and } \quad \dot{\xi}_{i}=\frac{1}{\tau_{i}}\left(\mu_{i} g(\sigma) S^{R}: \sigma-\xi_{i}\right)
$$

where $g(\sigma)$ is a non-linear function and $S^{R}$ is the viscous compliance, which are defined in the sequel. The weight and relaxation times of each elementary viscous mechanism $\left(\mu_{i}, \tau_{i}\right)$ define the temporal spectrum. These relaxation times are the classical ones from rheological models. As is classically observed with rheological models, this model needs a large number of viscous mechanisms to be fully representative of the complex viscous behavior of the laminated composites considered (in the rest of this paper 50 mechanisms are arbitrarily used). In order to simplify the identification of the temporal spectrum, a Gaussian spectrum form is used.

$$
\begin{gathered}
\forall i \in[1 ; N], \quad j=\frac{N_{2}-N_{1}}{N-1} *(i-1)+N_{1} \\
\tau_{i}=\exp (j) \text { and } \mu_{i}=\frac{\overline{\mu_{i}}}{\sum_{i} \overline{\mu_{i}}} \text { with } \overline{\mu_{i}}=\frac{1}{n_{0} \sqrt{\pi}} \exp \left(-\left(\frac{j-n_{c}}{n_{0}}\right)^{2}\right)
\end{gathered}
$$

where $N_{1}$ and $N_{2}$ are, respectively, the lower and upper boundaries used to numerically describe the time-space in the interval $[-\infty ;+\infty]$. The spectrum is based on only two parameters: $n_{c}$ the mean of the Gaussian spectrum and $n_{0}=\sqrt{2} s_{d}$ where $s_{d}$ is the standard deviation. The described spectrum was successfully used in the work by Maire [16] to model the viscoelastic behavior of Glass Fibre Reinforced Polymer during creep tests and in the work by Berthe [2] to model the strain rate dependency of CFRP at high strain rates. In order to simplify the identification, the viscous compliance is taken as a function of the elastic compliance $S^{0}$ :

$$
S^{R}=\left(\begin{array}{cccccc}
0 & 0 & 0 & 0 & 0 & 0 \\
0 & \beta_{22} S_{22}^{0} & 0 & 0 & 0 & 0 \\
0 & 0 & \beta_{33} S_{22}^{0} & 0 & 0 & 0 \\
0 & 0 & 0 & \beta_{44} S_{44}^{0} & 0 & 0 \\
0 & 0 & 0 & 0 & \beta_{55} S_{55}^{0} & 0 \\
0 & 0 & 0 & 0 & 0 & \beta_{66} S_{66}^{0}
\end{array}\right)
$$

It can be observed that no viscous behaviour is introduced in the first direction which is corresponding to the fiber orientation. Finally, to describe creep tests, a non-linear function $g(\sigma)$ has been introduced in [20]:

$$
g(\sigma)=1+\gamma\left(\sqrt{{ }^{t} \sigma: S^{R}: \sigma}\right)^{n}
$$

\subsection{2 | Model identification and simulation results}

The parameters of the model have been identified by performing FE model updating using Z-opt, which is part of Z-set. The experimental displacement time histories have been used as boundary conditions for the FE simulations. Table 5 summarizes the numerical values used for the Finite Element simulations. In this visco-elastic model, the considered value of $G_{12}$ corresponds to an asymptotic value of the modulus when viscous effects do not develop. Consequently, the identified value is necessarily 
higher than the experimental one. The visco-elastic spectrum used is extracted from [1]. Figure 6 compares the experimental and simulated results. Two axial stress-strain curves are plotted for the simulations. The first one is computed in the same way as in the experiments; i.e., the longitudinal load divided by the initial section and the strain is an average over a $2 \times 2 \mathrm{~mm}^{2}$ section corresponding to the strain gauge area. It is computed to be compared to the experimental results and is denoted " $F / S_{0}$ " in the graphs. The second one is the average of the stress and strain on the $2 \times 2 \mathrm{~mm}^{2}$ area of the strain gauge. This one is computed to determine whether the experimental stress-strain curves are representative of the local state at the center of the specimen. It is denoted as "local" in the graphs. The agreement between the $F / S_{0}$ model axial stress-strain curves and the experimental ones is quite reasonable. It can be seen that, by taking into account viscous effects, the experimental rigidity is better predicted for the $15^{\circ}$ off-axis test. However, there is a significant difference between the stress computed using the load and that computed in the gauge area by the FE simulations for the $15^{\circ}$ and $30^{\circ}$ off-axis specimens. In the $15^{\circ}$ simulation, the load based on axial stress is smaller than the local one by approximately $6 \%$. Interestingly, for the $30^{\circ}$ off-axis test, it is the local one that is smaller than the loadbased one by $2.5 \%$. Additionally, other stress components are not negligible in the simulations. Consequently, the computation of the local stress state can no longer be based on the uniform stress distribution along the cross section and corrections have to be computed to accurately evaluate the local stress applied experimentally on the material from the experimentally measured load.

TABLE 5 Numerical values used in the spectral visco-elastic model for $5 \mathrm{~mm} / \mathrm{min}$ simulations.

\begin{tabular}{cccccccc}
\hline$G_{12}$ & $E_{t}$ & $n_{c}$ & $n_{0}$ & $\gamma$ & $n$ & $\beta_{66}$ & $\beta_{22}$ \\
$5.56 \mathrm{GPa}$ & $7.5 \mathrm{GPa}$ & -2 & 9.5 & 4 & 3.22 & 0.66 & 0.2 \\
\hline
\end{tabular}

Figure 7 shows the axial stress and strain fields predicted by FE simulation for the $15^{\circ}$ off-axis specimen at the failure stress level. Figure 8 presents the axial stress computed along the failure line for all specimens. It can be seen that the stress in the failure section is reasonably homogeneous. It has a variation of less than $6 \%$ for the $15^{\circ}$ off-axis specimen and become more homogeneous with the off-axis angle. Thus, it can be concluded that a correction factor could be reasonably used in order to accurately compute the local stress applied to the material. Equation (9) explains how the corrected stress is computed using the correction factors determined with FE simulations. Table 6 summarizes the numerical values of the correction factors computed for the quasi-static tests.

$$
\sigma_{\text {corrected }}=\frac{F}{S_{0}}\left(\begin{array}{c}
\alpha_{x x} \\
\alpha_{y y} \\
\alpha_{x y}
\end{array}\right)
$$

where $\sigma_{\text {corrected }}$ is the corrected stress in the global frame and $\alpha_{x x}, \alpha_{y y}, \alpha_{x y}$ are the correction factors for all stress components. Finally, FE simulations have also been performed on $15^{\circ}$ specimens at the same strain-rate with an aspect ratio of 10. In this case, the correction factors obtained were very low $(0.2 \%$ on the axial stress). Consequently, the need for correction factors seems to be linked to the very low aspect ratio of the specimens considered in this study.

TABLE 6 Numerical values of the correction factors for quasi-static tests performed at a loading rate of $5 \mathrm{~mm} / \mathrm{min}$ for all specimen orientations.

\begin{tabular}{cccccc}
\hline$\theta$ & $15^{\circ}$ & $30^{\circ}$ & $45^{\circ}$ & $60^{\circ}$ & $75^{\circ}$ \\
\hline$\alpha_{x x}$ & 1.072 & 0.974 & 0.992 & 0.999 & $1+1.2 \cdot 10^{-4}$ \\
$\alpha_{y y}$ & $1.8 \cdot 10^{-2}$ & $-1.9 \cdot 10^{-2}$ & $-2.3 \cdot 10^{-3}$ & $-3.8 \cdot 10^{-4}$ & $-7.8 \cdot 10^{-7}$ \\
$\alpha_{x y}$ & $6.4 \cdot 10^{-4}$ & $-2.9 \cdot 10^{-2}$ & $-1.5 \cdot 10^{-2}$ & $-5.3 \cdot 10^{-3}$ & $4.3 \cdot 10^{-3}$ \\
\hline
\end{tabular}




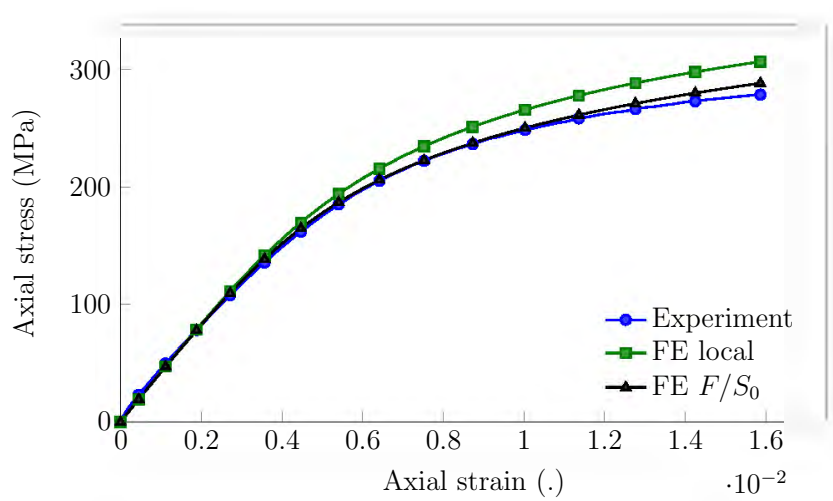

(a)

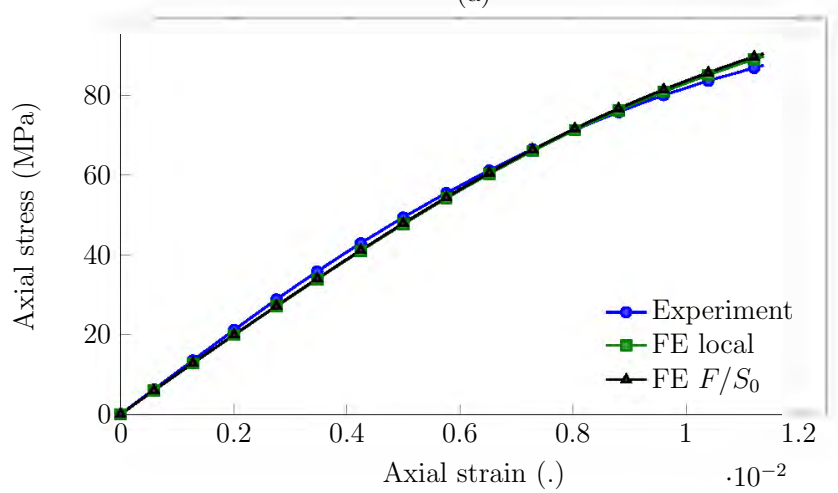

(c)

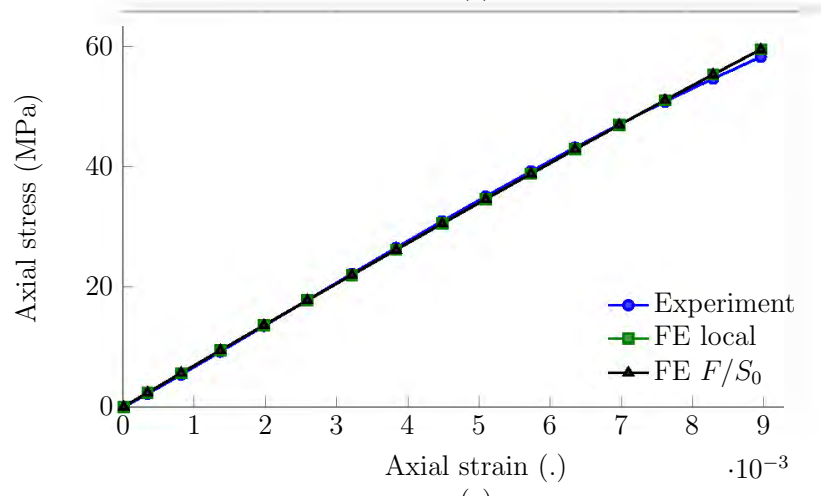

(e)

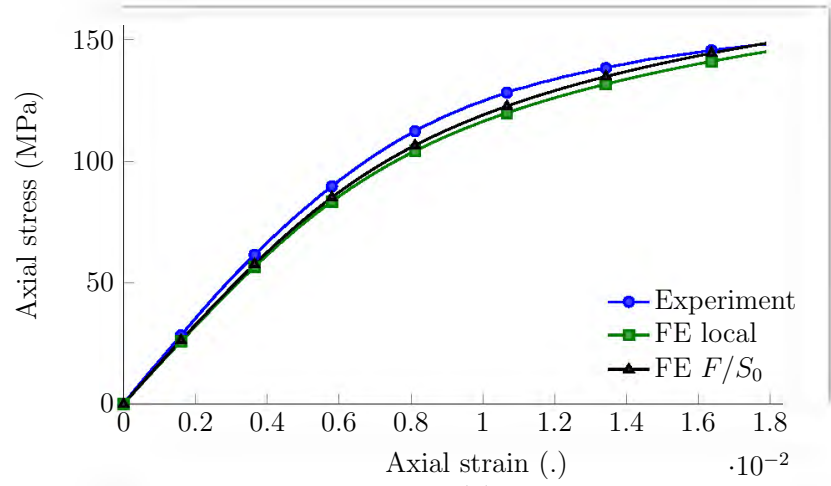

(b)

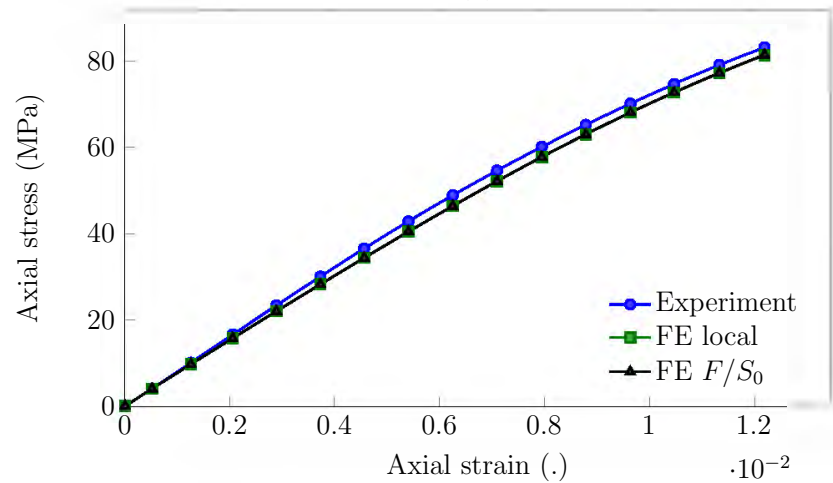

(d)

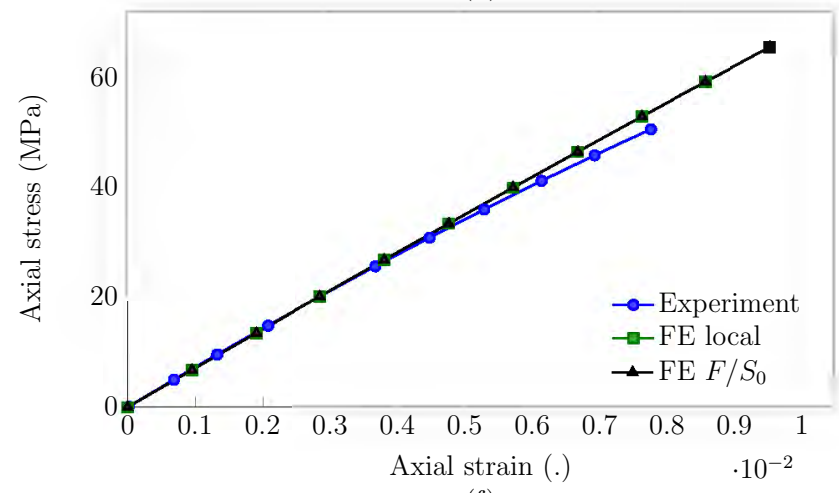

(f)

FIGURE 6 Comparison of experimental and FE simulated axial stress-strain curves with the visco-elastic model - (a) $15^{\circ}$ off-axis test - (b) $30^{\circ}$ off-axis test - (c) $45^{\circ}$ off-axis test - (d) $60^{\circ}$ off-axis test - (e) $75^{\circ}$ off-axis test - (f) $90^{\circ}$ test.

\section{2 | Failure stress state and fracture location}

One of the objectives of the present study is to investigate CRFP material strength under coupled shear and tension loadings. To compute the stress component according to the material axis, Equation (10) is used. Figure 9r(a) summarizes the axial material strength recorded as a function of the specimen angle. It also reports the non-linearity threshold determined using the method introduced by Castres et al. [4], to locate a $2 \%$ deviation with respect to a linear behavior. Figure 9 (b) summarizes the material stress states at failure computed assuming an homogeneous stress state and by using correction factors computed using the visco-elastic FE simulations. A significant difference is found between the assumed homogeneous stress state and the corrected one for $15^{\circ}$ off-axis tests. In these tests the axial failure stress of the $60^{\circ}$ off-axis specimen is at the same level as the $45^{\circ}$ one. This results in a large difference in Figure 9f(b). This is unusual, since in their studies Kawai and al. [10] and Taniguchi et al. 

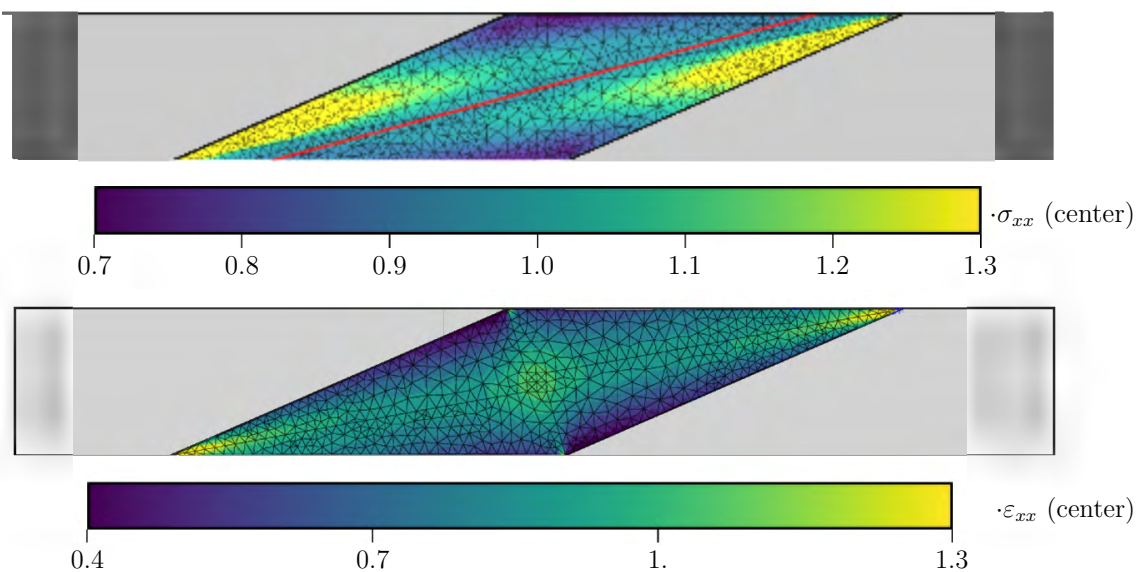

FIGURE 7 Axial stress field (top) and axial strain field (bottom) predicted by FE simulation of a $15^{\circ}$ off-axis specimen taking into account visco-elasticity. The red line represents the failure section at the center of the specimen along the fiber angle. The color bar legends are expressed as a multiple of the center axial stress and strain, whose values are $\sigma_{c}=320 \mathrm{MPa}$ and $\varepsilon_{c}=1.19 \cdot 10^{-2}$.

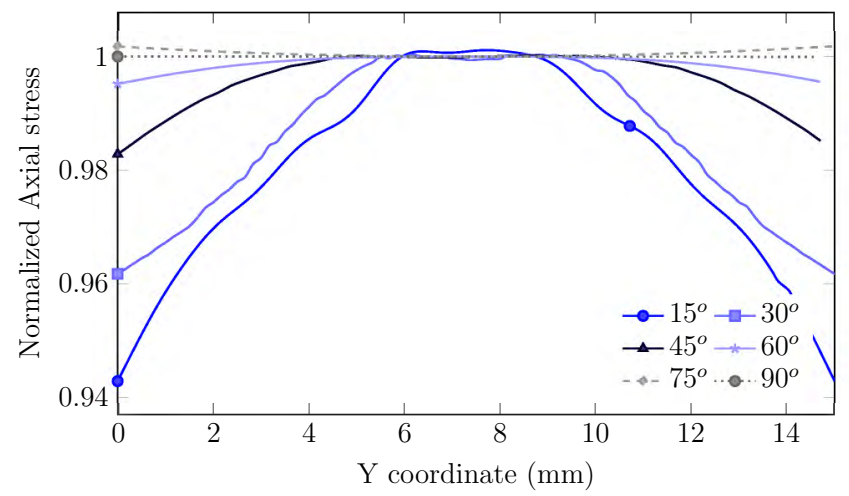

FIGURE 8 Normalized axial stress along the failure line predicted by FE simulation specimen taking into account the visco-elasticity. The axial stress is normalized by the stress value at the center of the specimen $\sigma_{c} . \sigma_{c}\left(15^{\circ}\right)=320 \mathrm{MPa}$, $\sigma_{c}\left(30^{\circ}\right)=150 \mathrm{MPa}, \sigma_{c}\left(45^{\circ}\right)=90 \mathrm{MPa}, \sigma_{c}\left(60^{\circ}\right)=85 \mathrm{MPa}, \sigma_{c}\left(75^{\circ}\right)=62 \mathrm{MPa}, \sigma_{c}\left(90^{\circ}\right)=54 \mathrm{MPa}$

[26] recorded $60^{\circ}$ off-axis axial failure stresses below those for $45^{\circ}$. For other angles it is consistent with these studies and with that observed by Vargas and Mujika [30].

$$
\left(\begin{array}{c}
\sigma_{L} \\
\sigma_{T} \\
\sigma_{L T}
\end{array}\right)=\left(\begin{array}{ccc}
\cos ^{2} \theta & \sin ^{2} \theta & -2 \cos \theta \sin \theta \\
\sin ^{2} \theta & \cos ^{2} \theta & 2 \cos \theta \sin \theta \\
\cos \theta \sin \theta & -\cos \theta \sin \theta & \cos ^{2} \theta-\sin ^{2} \theta
\end{array}\right)\left(\begin{array}{l}
\sigma_{x x} \\
\sigma_{y y} \\
\sigma_{x y}
\end{array}\right)
$$

The fracture location is obviously critical in tests designed to characterize the material strength, especially for such low aspect ratio specimens. Figure 10 summarizes the fracture location for all $5 \mathrm{~mm} / \mathrm{min}$ loading rate tests. It can be seen that most of the failures occur in the gauge section. Interestingly, for all $15^{\circ}$ off-axis specimens the failure occurred in the interest area, although it is the case in which the stress state is the most heterogeneous in FE simulations.

\subsection{Homogeneity of the axial strain field}

Axial strain fields are computed using digital image correlation (DIC) in order to assess the homogeneity of the strain field prior to the failure. The DIC is performed using the Onera escale platform, which is dedicated to the dialogue between experiments 


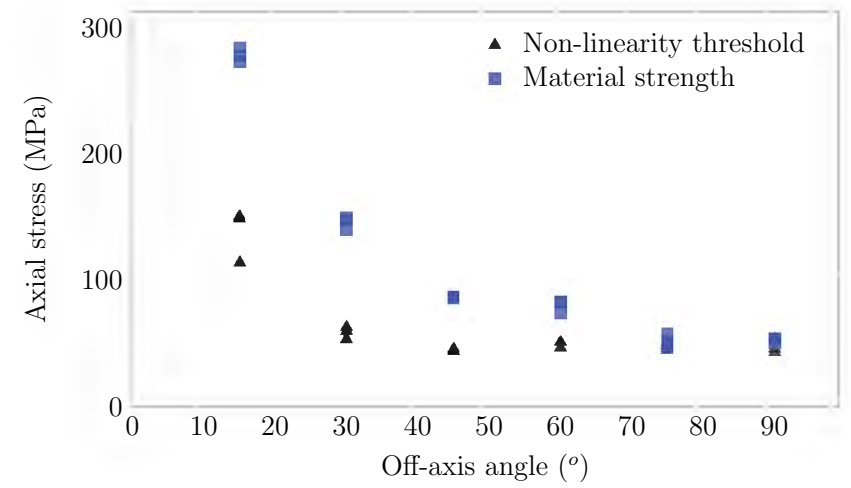

(a)

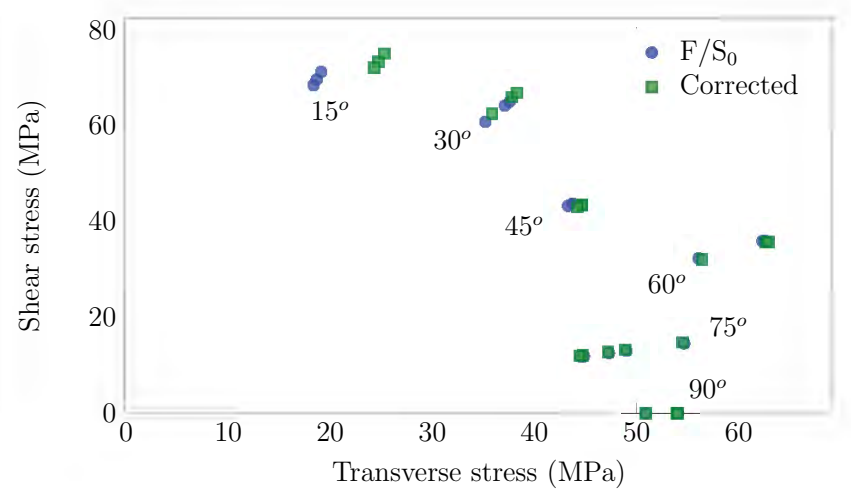

(b)

FIGURE 9 Failure stress assuming a homogeneous stress state, corrected using FE simulation for $5 \mathrm{~mm} / \mathrm{min}$ tests.

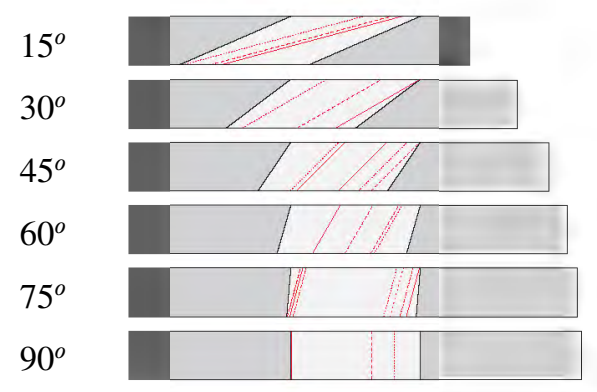

FIGURE 10 Location of the final failure in the off-axis tension specimen at $5 \mathrm{~mm} / \mathrm{min}$.

and simulations. The DIC is performed using the software FOLKI-D, which uses local method and provides dense fields [13]. A subset size of 20 pixels has been used for the strain computation. Figure 11 summarizes typical axial strain maps recorded prior to the failure for all tested angles. Bands of higher axial strain can be observed for angles ranging from $15^{\circ}$ to $60^{\circ}$. These bands are oriented along the fiber direction. For the $15^{\circ}$ specimen the size of the band corresponds to the area that can geometrically deform freely in shear. For the $30^{\circ}$ off-axis test, this area is already very large and several localized shear bands were observed during the test. Except for these bands the axial strain field is quite homogeneous.

\section{I EXPERIMENTAL INVESTIGATION OF LOADING RATE INFLUENCE}

Once the specimen geometry was validated for the slowest loading rates, tests were performed at higher loading rates of $500 \mathrm{~mm} / \mathrm{min}$ and $1 \mathrm{~m} / \mathrm{s}$. For high actuator speeds, the load signal can be perturbed by the mechanical resonance of the loading chain. The natural frequencies of the loading chain, including the load cell, had previously been characterized. To minimize the effect of this resonance on the various high loading rate signals, a bandstop Butterworth first order filter is applied between 5000 and $8000 \mathrm{~Hz}$ on all load signals recorded for $1 \mathrm{~m} / \mathrm{s}$ tests. Figure 12 shows an example of a load signal before and after using a filter for a $15^{\circ}$ off-axis specimen. It can be seen that the filter effect is very reasonable, especially in the frequency domain. Additionally, it does not greatly affect the maximal value, which is used to compute the material strength. Figure 13 summarizes typical stress-strain curves for all tested off-axis specimen orientations and all actuator loading rates. For orientations ranging from $15^{\circ}$ to $60^{\circ}$, a progressive increase in the apparent modulus is observed with the strain rate. It is less visible in the $75^{\circ}$ and $90^{\circ}$ tests. This observation is consistent with the use of a visco-elastic model that can differentiate strain-rate dependency in both $0^{\circ}$ and $90^{\circ}$ tension directions and shear. 


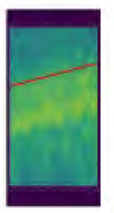

(a)

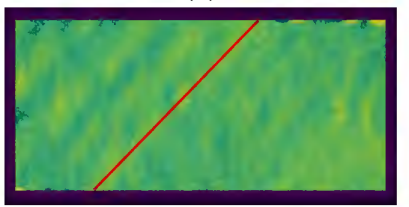

(c)

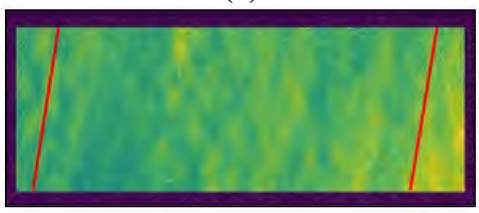

(e)
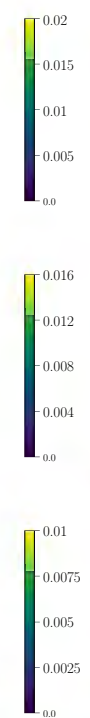

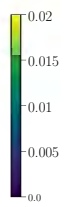

(b)

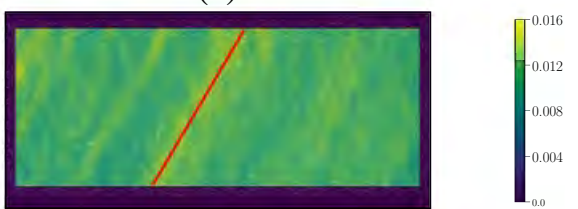

(d)

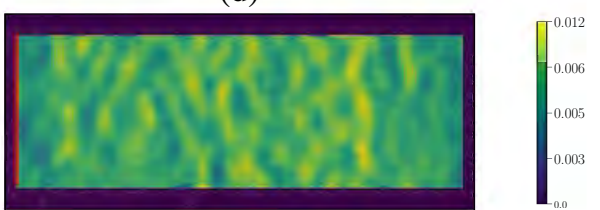

(f)

FIGURE 11 Typical axial strain fields recorded using DIC prior to the failure of the specimen - (a) $15^{\circ}$ off-axis test - (b) $30^{\circ}$ off-axis test - (c) $45^{\circ}$ off-axis test - (d) $60^{\circ}$ off-axis test - (e) $75^{\circ}$ off-axis test - (f) $90^{\circ}$ test. The red line indicates the failure location. The strain fields correspond to axial strain levels measured by strain gauges of $\varepsilon_{15^{\circ}}=0.0159, \varepsilon_{30^{\circ}}=0.0131, \varepsilon_{45^{\circ}}=$ $0.0113, \varepsilon_{60^{\circ}}=0.0113, \varepsilon_{75^{\circ}}=0.0067$ and $\varepsilon_{90^{\circ}}=0.0079$.

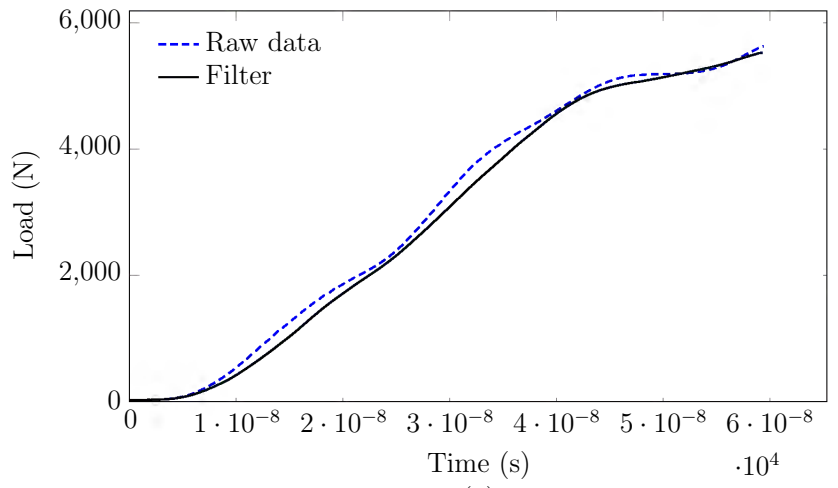

(a)

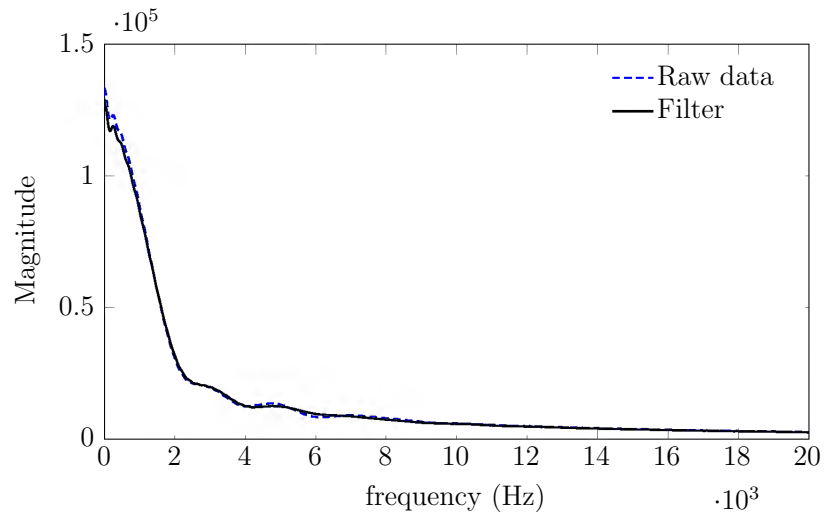

(b)

FIGURE 12 (a) Effect of the Butterworth filter on the load signal - (b) Fast Fourier Transform of the signals for a $1 \mathrm{~m} / \mathrm{s} 15^{\circ}$

off-axis test.

\section{1 | Visco-elastic simulations}

As for the low stroke rate, FE simulations are used to determine the local stress states in the $15^{\circ}$ and $30^{\circ}$ off-axis tests with such low aspect ratio specimens. In the sequel, a new set of viscous parameters is used, specifically identified considering all the loading rates to accurately describe the rate dependency of the material as the previous identification was dedicated only to quasi-static loading rates. Table 7 summarizes the numerical values identified in the same way as in Section 4.1.2, i.e., by FE model updating. Figure 14 compares the FE simulations with the experimental results. Since almost no dependencies are observed in the $75^{\circ}$ and $90^{\circ}$ tests (which compares well with the simulations), the comparison focuses on $15^{\circ}, 30^{\circ}, 45^{\circ}$ and $60^{\circ}$ specimens. The agreement between the " $F / S_{0}$ " FE axial stress and the experimental one is quite reasonable. The increase 


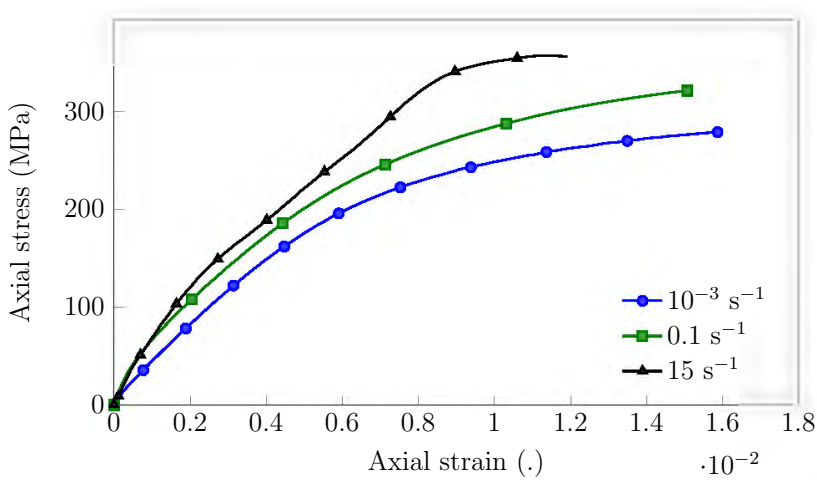

(a)

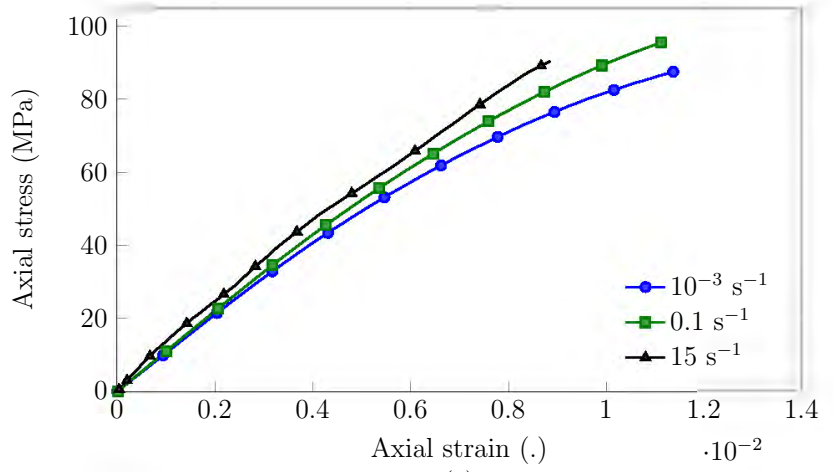

(c)

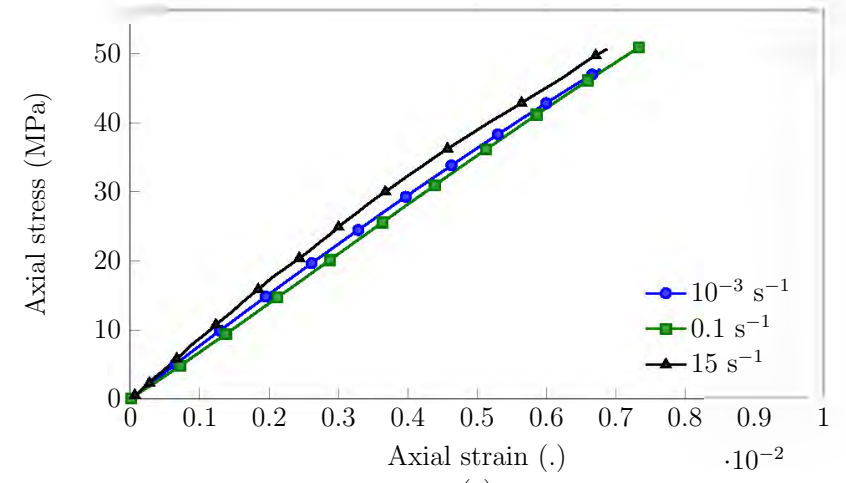

(e)

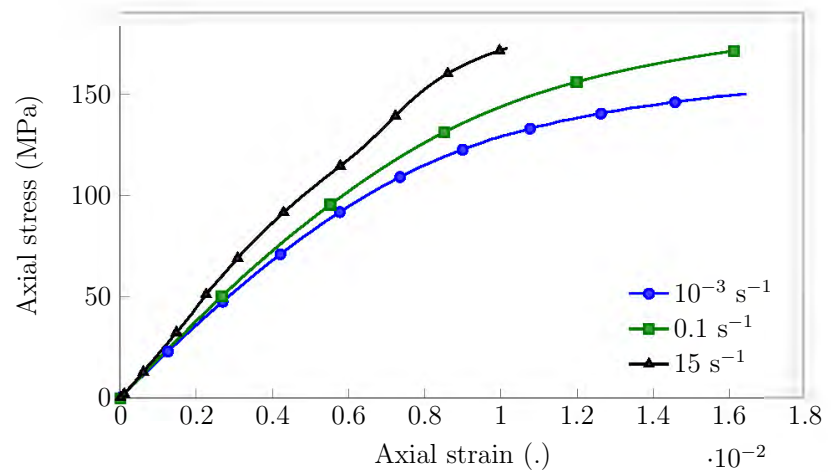

(b)

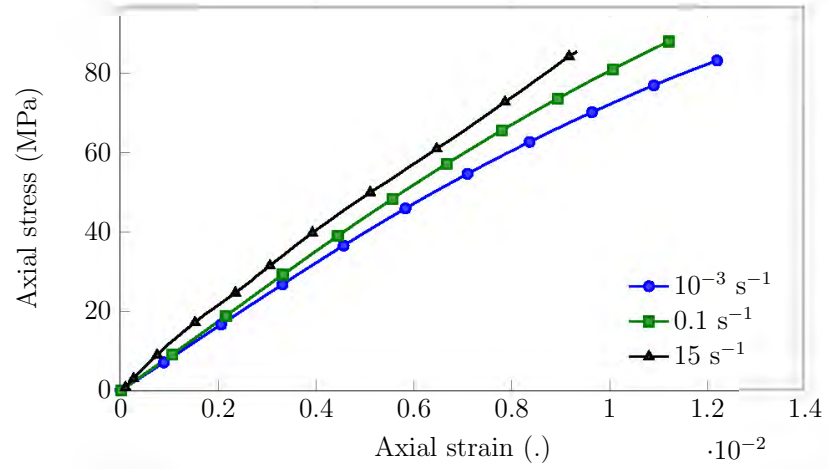

(d)

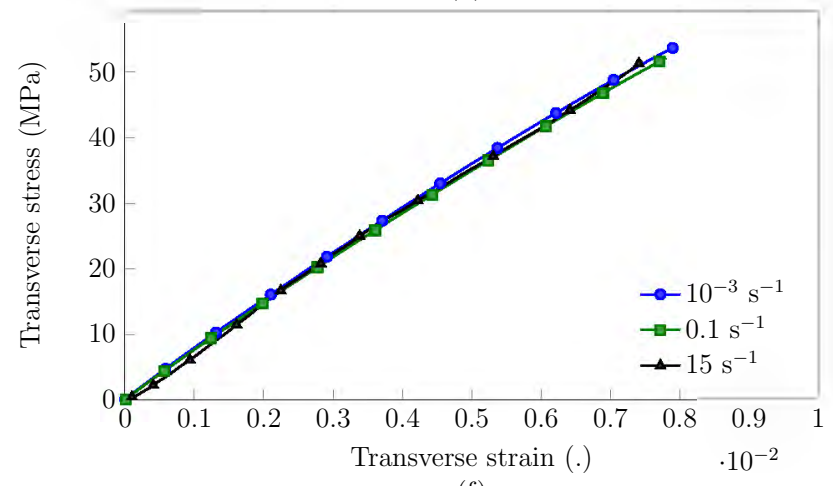

(f)

FIGURE 13 Typical stress-strain curves recorded in off-axis tension tests at several stroke rates - (a) $15^{\circ}$ off-axis test - (b) $30^{\circ}$

off-axis test - (c) $45^{\circ}$ off-axis test - (d) $60^{\circ}$ off-axis test - (e) $75^{\circ}$ off-axis test - (f) $90^{\circ}$ tests.

of the apparent modulus with the strain-rate observed experimentally is well reproduced by the model. Globally, the non-linear behavior is also reasonably well predicted. The exception is the response at $45^{\circ}$ which is slightly overestimated.

\section{2 $\quad$ Failure stress states and fracture locations}

Figure 15 summarizes the axial material strengths for all performed tests. Figure 16 summarizes the fracture locations for all tests performed for an actuator speed of $500 \mathrm{~mm} / \mathrm{min}$ and $1 \mathrm{~m} / \mathrm{s}$. It can be seen that there is a clear increase in the axial failure stress for specimens oriented at $15^{\circ}$ and $30^{\circ}$. For other specimen orientations the tendencies are less clear since the experimental scatter becomes more significant. For instance: 
TABLE 7 Numerical values used for the spectral visco-elastic model obtained for an identification procedure on all tests.

\begin{tabular}{cccccccc}
\hline$G_{12}$ & $E_{t}$ & $n_{c}$ & $n_{0}$ & $\gamma$ & $n$ & $\beta_{66}$ & $\beta_{22}$ \\
$5.98 \mathrm{GPa}$ & $7.5 \mathrm{GPa}$ & -2 & 7.44 & 5.09 & 2.3 & 0.50 & 0.1 \\
\hline
\end{tabular}

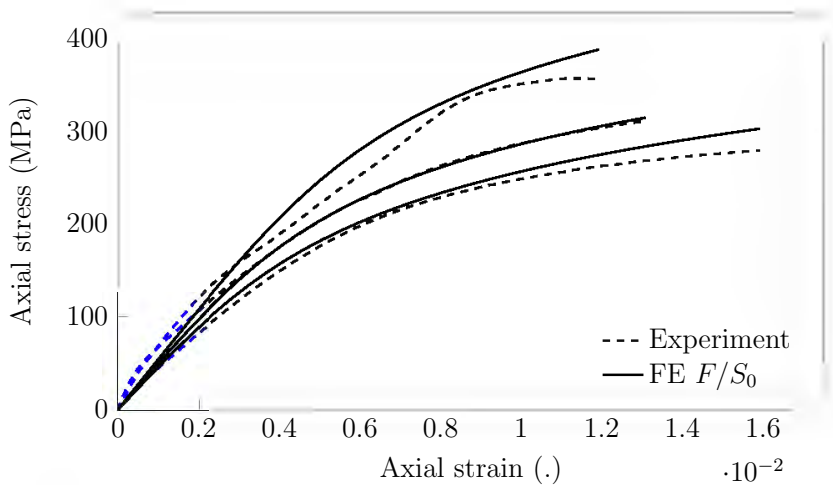

(a)

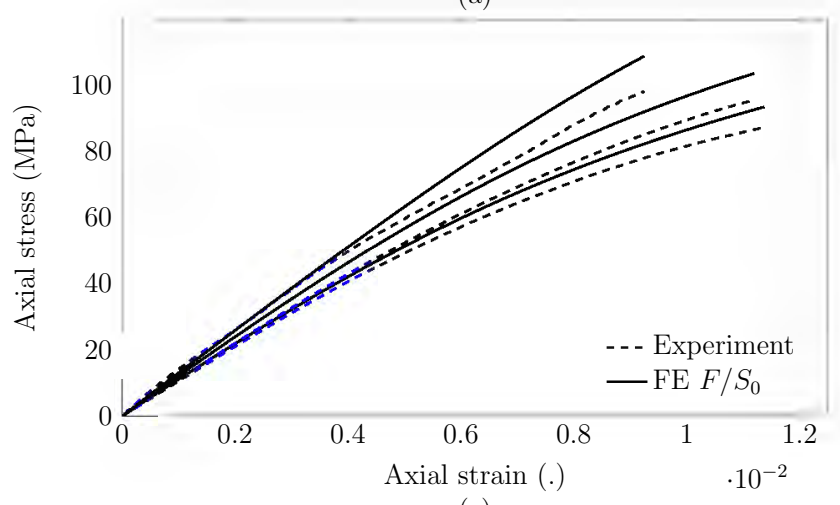

(c)

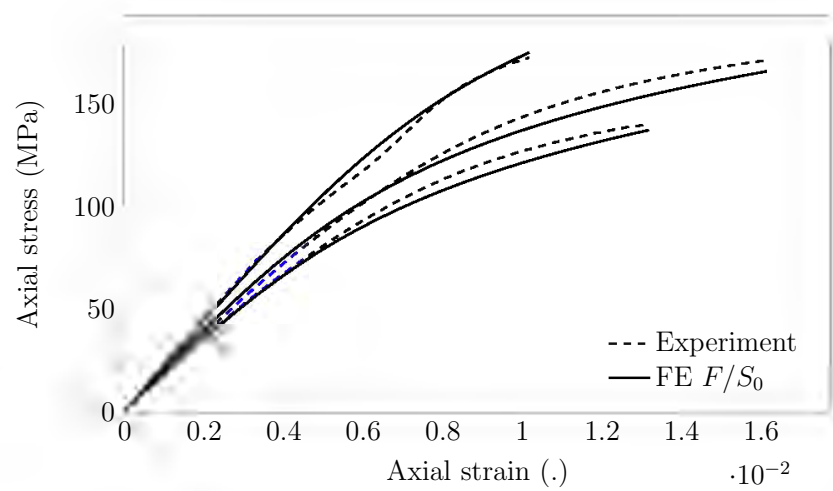

(b)

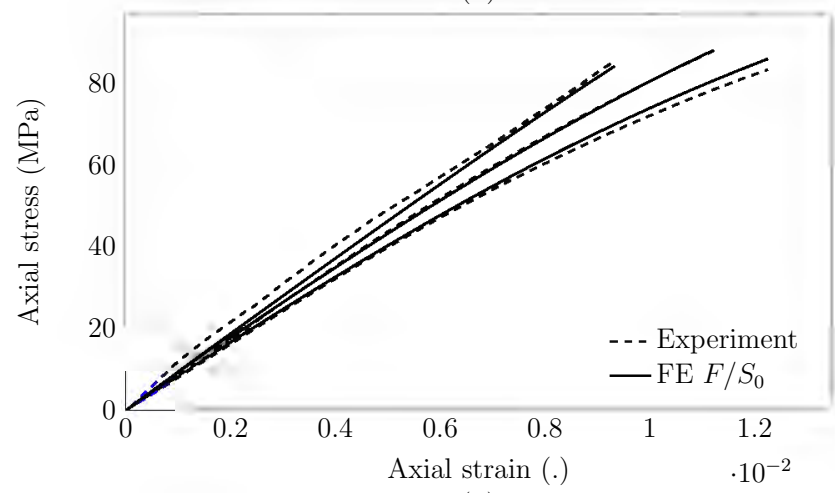

(d)

FIGURE 14 Comparison of experimental and FE simulated axial stress-strain curves with the visco-elastic model for all tested

loading rates - (a) $15^{\circ}$ off-axis test - (b) $30^{\circ}$ off-axis test - (c) $45^{\circ}$ off-axis test - (d) $60^{\circ}$ off-axis tests.

- at $45^{\circ}$ the strength recorded in all tests performed at $0.1 \mathrm{~s}^{-1}$ is greater than that recorded at $10^{-3} \mathrm{~s}^{-1}$. However, the scatter of those recorded at $15 \mathrm{~s}^{-1}$ is large. There are some tests which have failed at the junction with the tabs and at the same stress as the $10^{-3} \mathrm{~s}^{-1}$ tests and one that failed in the gauge area at a stress greater than those at $0.1 \mathrm{~s}^{-1}$.

- at $60^{\circ}$ the scatter in the tests makes it difficult to reach a conclusion: while at a loading rate of $10^{-3} \mathrm{~s}^{-1}$ all specimens failed in the gauge section; at $0.1 \mathrm{~s}^{-1}$ only one failed in the gauge section, while the others failed at the junction with the tabs. The one that failed at the junction with the tabs has a failure stress superior to the ones at $10^{-3} \mathrm{~s}^{-1}$ while the others are similar. At $15 \mathrm{~s}^{-1}$ all specimens failed at the junction with the tabs.

- at $75^{\circ}$ most specimens failed in the gauge section for all of the tested strain rates and an increase in the failure stress with the strain-rate can be observed.

- at $90^{\circ}$ the mean of the failure stress at $0.1 \mathrm{~s}^{-1}$ is greater than that at $10^{-3} \mathrm{~s}^{-1}$, and all of the specimens failed in the gauge section. However, the scatter is larger at $0.1 \mathrm{~s}^{-1}$ than at $10^{-3} \mathrm{~s}^{-1}$. At $15 \mathrm{~s}^{-1}$, all specimen failed at the junction with the 
tabs. One of these failed at a stress greater than all others recorded, while the other two lay near the lower levels recorded at $10^{-3} \mathrm{~s}^{-1}$.

Overall, an increase of the axial failure stress with the strain-rate is observed for all orientations. It is larger for the $15^{\circ}$ off-axis specimens and decreases while the specimen off-axis angle increases.

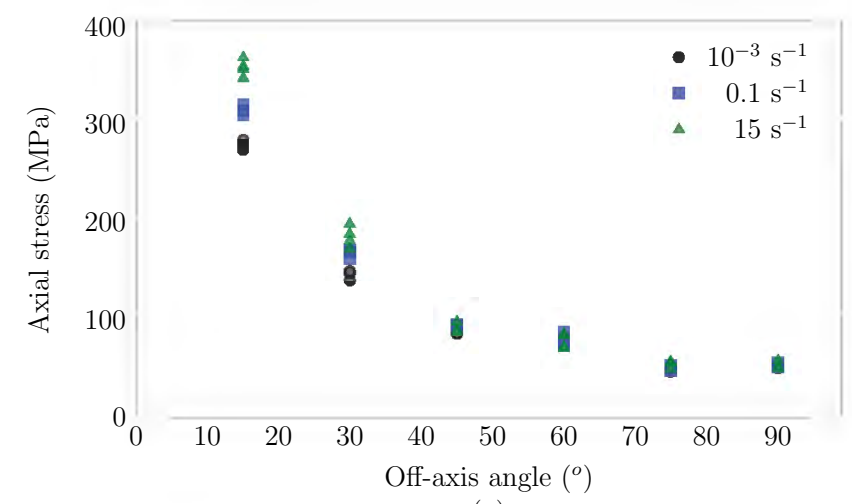

(a)

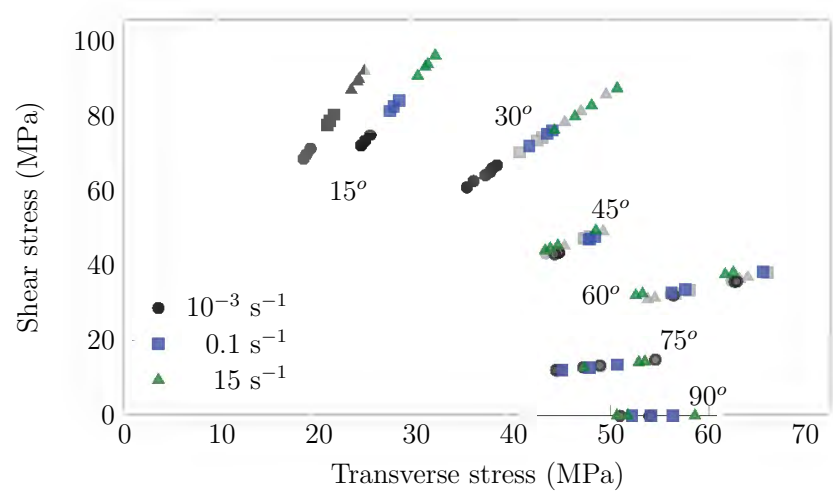

(c)

FIGURE 15 T700/M21 tensile strength - (a) uncorrected as a function of the specimen angle - (b) corrected using the FE simulations presented in a shear stress versus transverse stress graph (not corrected in transparency).
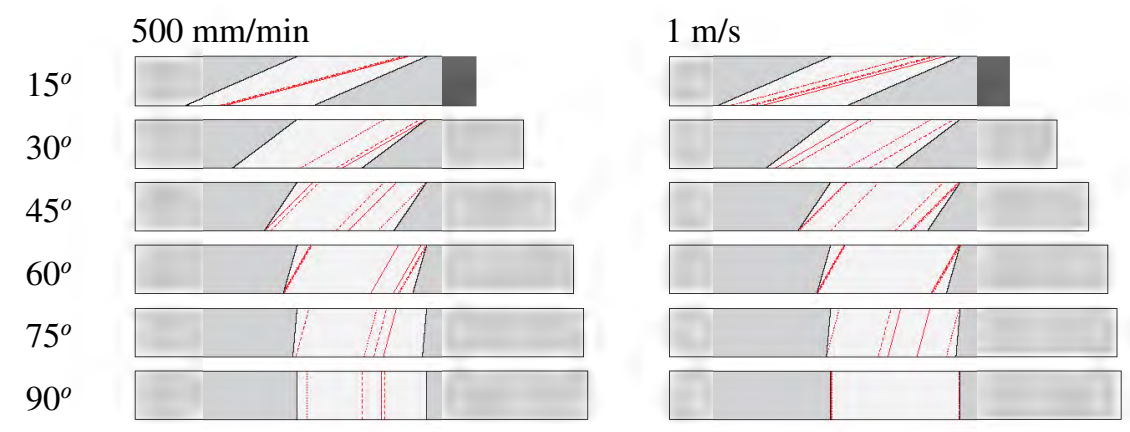

FIGURE 16 Location of the final failure in the off-axis tension specimen loaded at $500 \mathrm{~mm} / \mathrm{min}$ and $1 \mathrm{~m} / \mathrm{s}$.

\section{I DISCUSSION}

Globally, the scatter of the results is larger for off-axis specimens with an angle between $45^{\circ}$ and $90^{\circ}$, especially for the higher tested stroke-rates. This is often the case in high stroke rate tests. However, in the present case slight differences in the axial failure stress result in large differences when plotted in the shear stress vs. transverse stress graph. Also, the properties of the material must be known in order to compute the angles of the oblique tabs. In the present work, properties determined in another study on another batch of material have been used. Fortunately, this difference induced only very slight changes in the tab angle. It is worth noticing that this difference is maximal for $60^{\circ}$ specimens which exhibit a high failure stress compared to the other angles. However, as pointed out by Taniguchi et al. [26] the shear modulus increases with the strain rate so the tab angles should 
be adapted. Thus, maybe the tab angles are not suitable for the highest tested strain-rates. Additionally, these tabs are designed to homogenize the stress field, but the angle computation is based on a linear elastic assumption, which is not valid up to the failure of the specimen. The combination of all of these elements may be the cause of the differences in the axial failure stress and location observed.

In the present study, visco-elastic FE simulations have been used to take into account the end constraint effect in the determination of the failure stress state. However, taking the experimental end constraint into account accurately in FE simulation is complicated. Especially in these tests, the area near the tab is hidden by the clamping device so DIC measurement cannot be used. In the present work, these end constraints have been idealized. In addition, the axial strain fields recorded using DIC are quite different from those predicted by the FE simulations. For instance, localized shear bands are visible in the experimental axial strain fields. The cause of these bands is not clear (material inhomogeneities, free edge effects, rich resin areas, etc.), but the final failure occurs in these bands. Other methods, such as the virtual field method for strength identification [6], which free the identification from the necessity of modelling the end-constraint, or the data-driven framework [15], which does not rely on a constitutive equation to determine the stress distribution, might be interesting to process these test data into material stress-strain states.

\section{7 | CONCLUSIONS}

In the present study off-axis and transverse tests have been performed on T700/M21 CFRP material. The chosen specimens have a very low aspect ratio of 2.66 in order to maximize the achievable strain-rate while maintaining a reasonable 15 mm specimen width to limit possible free edge effects.

It has been shown that FE simulations using a spectral visco-elastic model permit the axial stress-strain curves to be described at all tested strain-rates. It was first identified on quasi-static results to model the non-linearity of the stress-strain response. In particular, in the $15^{\circ}$ off-axis test the apparent modulus is not in agreement with that predicted by the transformation law. This difference is correctly predicted by the visco-elastic model. Thus, it was calibrated using all tests, with a fairly good agreement. Using this model, corrections of the stress field were computed to take into account the effect of the end constraint. The effect of the correction is maximal for the $15^{\circ}$ off-axis test, and it decreases while the off-axis angle increases becoming negligible for the $75^{\circ}$ and $90^{\circ}$ tests.

An important conclusion of this work is that for low aspect ratio off-axis specimens the local failure stress cannot be directly obtained from the global experimental data. The present work propose a methodology using correction factors that can be used to accurately evaluate the local stress applied to the material in this case.

The proposed methodology is then considered in order to study the loading rate influence on the observed failure stress. Globally, an increase in the axial failure stress with the strain rate was observed for all specimen orientations. It is greater for $15^{\circ}$ specimens and decreases with the specimen angle. Thus, it can be concluded that the rate effect is more pronounced for the shear strength than for the transverse strength. Further work will focus on the modeling of the dependency of the failure criterion on the strain-rate.

\section{8 | ACKNOWLEDGEMENT}

The authors gratefully acknowledge the funding from the French Civil Aviation Directorate (DGAC). They also gratefully acknowledge the Hauts-de-France Region for funding equipment that contributed to this research work. The authors also wish to thank Mr. M. Ragonet for the care that he took in performing the experimental tests.

\section{References}

[1] Berthe, J., 2013: Comportement thermo-visco-élastique des composites CMO-De la statique à la dynamique grande vitesse. Ph.D. thesis, Ecole centrale de Lille. 
[2] Berthe, J., M. Brieu, and E. Deletombe, 2013: Improved viscoelastic model for laminate composite under static and dynamic loadings. Journal of Composite Materials, 47, no. 14, 1717-1727.

[3] Cai, D., X. Wang, J. Deng, and G. Zhou, 2017: Coupling coefficients of glass/epoxy laminates under off-axis tensile conditions: Experimental verification. Polymer Testing, 63, 334-341, doi:https://doi.org/10.1016/j.polymertesting.2017.08.041. URL http://www.sciencedirect.com/science/article/pii/S0142941817310280

[4] Castres, M., J. Berthe, E. Deletombe, and M. Brieu, 2017: Experimental evaluation of the elastic limit of carbon-fibre reinforced epoxy composites under a large range of strain rate and temperature conditions. Strain, 53, no. 6, e12248.

[5] Daniel, I., B. Werner, and J. Fenner, 2011: Strain-rate-dependent failure criteria for composites. Composites Science and Technology, 71, no. 3, $357-364$.

[6] Fletcher, L. and F. Pierron, 2018: An image-based inertial impact (ibii) test for tungsten carbide cermets. Journal of Dynamic Behavior of Materials, 4, no. 4, 481-504.

[7] Hinton, M. and A. Kaddour, 2012: The background to the second world-wide failure exercise. Journal of Composite Materials, 46, no. 19-20, 2283-2294.

[8] ISO, B. et al., 1997: Plastics-determination of tensile properties.

[9] Kaddour, A., M. Hinton, P. Smith, and S. Li, 2013: A comparison between the predictive capability of matrix cracking, damage and failure criteria for fibre reinforced composite laminates: Part a of the third world-wide failure exercise. Journal of Composite Materials, 47, no. 20-21, 2749-2779.

[10] Kawai, M., M. Morishita, H. Satoh, S. Tomura, and K. Kemmochi, 1997: Effects of end-tab shape on strain field of unidirectional carbon/epoxy composite specimens subjected to off-axis tension. Composites Part A: Applied Science and Manufacturing, 28, no. 3, 267-275.

[11] Koerber, H., P. Kuhn, M. Ploeckl, F. Otero, P.-W. Gerbaud, R. Rolfes, and P. Camanho, 2018: Experimental characterization and constitutive modeling of the non-linear stress-strain behavior of unidirectional carbon-epoxy under high strain rate loading. Advanced Modeling and Simulation in Engineering Sciences, 5, no. 1, 17, doi:10.1186/s40323-018-0111-x. URL https://doi.org/10.1186/s40323-018-0111-x

[12] Koerber, H., J. Xavier, and P. Camanho, 2010: High strain rate characterisation of unidirectional carbon-epoxy im7-8552 in transverse compression and in-plane shear using digital image correlation. Mechanics of Materials, 42, no. 11, 1004-1019.

[13] Le Besnerais, G., Y. Le Sant, and D. Lévêque, 2016: Fast and dense 2d and 3d displacement field estimation by a highly parallel image correlation algorithm. Strain, 52, no. 4, 286-306.

[14] Leong, M., L. C. Overgaard, I. Daniel, E. Lund, and O. Thomsen, 2013: Interlaminar/interfiber failure of unidirectional glass fiber reinforced composites used for wind turbine blades. Journal of Composite Materials, 47, no. 3, 353-368.

[15] Leygue, M., A.and Coret, J. Réthoré, L. Stainier, and E. Verron, 2018: Data-based derivation of material response. Computer Methods in Applied Mechanics and Engineering, 331, 184-196.

[16] Maire, J.-F., 1992: Etudes théorique et expérimentale du comportement de matériaux composites en contraintes planes. Ph.D. thesis, Besançon.

[17] Missoum-Benziane, D., V. Chiaruttini, J.-D. Garaud, F. Feyel, R. Foerch, N. Osipov, S. Quilici, J. Rannou, A. Roos, and D. Ryckelynck, 2011: Z-set/zebulon: une suite logicielle pour la mécanique des matériaux et le calcul de structures. 10e colloque national en calcul des structures, 8-p.

[18] Mujika, F., 2005: New considerations on the stress field in an off-axis tensile test. Journal of composite materials, 39, no. 21, 1909-1929.

[19] Ninan, L., J. Tsai, and C. Sun, 2001: Use of split hopkinson pressure bar for testing off-axis composites. International Journal of Impact Engineering, 25, no. 3, 291-313. 
[20] Petipas, C., 2000: Analyse et prévision du comportement à long terme des composites fibres de carbone/matrice organique. These de doctorat de l'Universite de Franche-Comte.

[21] Pierron, F. and A. Vautrin, 1996: The 10 off-axis tensile test: a critical approach. Composites Science and Technology, 56, no. 4, 483-488.

[22] Raimondo, L., L. Iannucci, P. Robinson, and P. Curtis, 2012: Modelling of strain rate effects on matrix dominated elastic and failure properties of unidirectional fibre-reinforced polymer-matrix composites. Composites Science and Technology, 72, no. 7, 819-827.

[23] Soden, P., A. Kaddour, and M. Hinton, 2004: Recommendations for designers and researchers resulting from the worldwide failure exercise. Composites Science and Technology, 64, no. 3, 589-604.

[24] Song, B., W. Chen, and T. Weerasooriya, 2003: Quasi-static and dynamic compressive behaviors of a s-2 glass/sc15 composite. Journal of Composite Materials, 37, no. 19, 1723-1743.

[25] Sun, C. and I. Chung, 1993: An oblique end-tab design for testing off-axis composite specimens. Composites, 24, no. 8, 619-623.

[26] Taniguchi, N., T. Nishiwaki, and H. Kawada, 2007: Tensile strength of unidirectional cfrp laminate under high strain rate. Advanced Composite Materials, 16, no. 2, 167-180.

[27] Tao, Y., H. Chen, K. Yao, H. Lei, Y. Pei, and D. Fang, 2017: Experimental and theoretical studies on inter-fiber failure of unidirectional polymer-matrix composites under different strain rates. International Journal of Solids and Structures, 113, $37-46$.

[28] Tsai, J. and C. Sun, 2004: Dynamic compressive strengths of polymeric composites. International Journal of Solids and Structures, 41, no. 11, 3211-3224.

[29] - 2005: Strain rate effect on in-plane shear strength of unidirectional polymeric composites. Composites science and technology, 65, no. 13, 1941-1947.

[30] Vargas, G. and F. Mujika, 2010: Determination of in-plane shear strength of unidirectional composite materials using the off-axis three-point flexure and off-axis tensile tests. Journal of Composite Materials, 44, no. 21, $2487-2507$. 